\title{
PREGNANCY RELATIONSHIP THROUGH THE MONTHS THE EVENT OF THE NEONATORUM ASFIXIA IN BULUKUMBA DISTRICT
}

\author{
A. Nurlaily ${ }_{2}$ Irmawati $^{2}$ \\ ${ }^{I}$ Department of Midwifery, Stikes Panrita Husada Bulukumba, Indonesia \\ ${ }^{2}$ Department of Midwifery, Stikes Panrita Husada Bulukumba, Indonesia \\ Corresponding author: A.Nurlaily \\ Email: andinurlaily@gmail.com
}

\begin{abstract}
Post date pregnancy is one of the pregnancies that are at risk, this case can cause many risks and the higher complication either for mothers or the baby who had beenborn couldhave asphyxia. The purpose of the study is to find out the relationship of post date pregnancy and the incident of asphyxia neonatorum. The type of the study used was analytic survey with historical cohort research design. The population sample was all maternity mothers in RSUD H. A. Sulthan Daeng Radja Bulukumba 2016 was 1526. The sample was 307 people. The sampling technique used is probability sampling with systematic random sampling. The instrument taking used was performed through observation. Data were analyzed by ChiSquare $\left(\mathrm{X}^{2}\right)$ with $\alpha 0.05$ and Relative Risk test (RR). The result of this study found that the analyzed by Chi Square test obtained (p-value: 0,00) and relative risk value 3.066. which means that there was relationship of post date pregnancy and the incident of asphyxia neonatorum in RSUD H. A. Sulthan Daeng Radja Bulukumba 2016, with a relative risk value (RR) of 3.066 means that mothers who have a post date at risk 3 times more childbearing asphyxia compared with pregnant aterm. It is recommented for midwifes to be more cautions in determining the age of the pregnancy so that the incident of the asphyxia neonatorum can be minimized.
\end{abstract}

Keywords: Post Date Pregnancy, Asphyxia Neonatorum 


\section{PENDAHULUAN}

Asfiksia neonatorum adalah suatu keadaan dimana bayi baru lahir tidak dapat bernafas secara spontan dan teratur setelah lahir. Dampak berkepanjangan yang bisa terjadi akibat asfiksia adalah kerusakan otak berupa hipoksik iskemik enselopati, edema serebri, palsi serebralis. Asfiksia juga dapat mempengaruhi fungsi organ vital lainnya seperti jantung, ginjal dan dapat menyebabkan perdarahan paru, edema paru bahkan kematian (Manggiasih \& Pongki, 2016).

Kehamilan lewat bulan (postmatur atau postterm), yaitu kehamilan yang berlangsung selama 42 minggu atau 294 hari atau lebih (Oxorn \& William, 2010). Permasalahan yang terjadi pada kehamilan lewat bulan adalah plasenta yang tidak sanggup memberikan nutrisi dan pertukaran $\mathrm{CO}_{2}$. Makin menurunnya sirkulasi darah menuju sirkulasi plasenta dapat mengakibatkan pertumbuhan janin makin lambat, terjadinya metabolisme janin, air ketuban makin kental, berkurangnya nutrisi $\mathrm{O}_{2}$ ke janin yang menimbulkan asfiksia dan setiap saat dapat meninggal dalam rahim, saat persalinan janin lebih mudah mengalami asfiksia (Nurmayawati, 2014).

Menurut World Health Organization (WHO) tahun 2013, sekitar 15 juta bayi dilahirkan didunia setiap tahun. Lebih satu juta dari bayi tersebut meninggal segera setelah dilahirkan, dan banyak yang tidak terhitung jumlahnya menderita kecatatan sepanjang hayat secara fisik atau fisiologis. (Depkes RI, 2012). Tahun 2014 Angka Kematian bayi menjadi indikator pertama dalam menentukan derajat kesehatan anak dan setiap tahunnya kira-kira 3\% (3,6 juta) dari 120 juta bayi baru lahir mengalami asfiksia, hampir 1 juta bayi meninggal (WHO, dikutip dalam Brillianningtyas et al, 2013).

Menurut hasil Survei Demografi dan Kesehatan Indonesia (SDKI) tahun 2012 menunjukkan Angka Kematian Neonatus (AKN) sebesar 19 per 1.000 kelahiran hidup. Angka Kematian Bayi (AKB) sebesar 32 per 1. 000 kelahiran hidup. Hasil Survei Penduduk Antar Sensus (SUPAS) 2015 menunjukkan AKB sebesar 22,23 per 1.000 kelahiran hidup, yang artinya sudah mencapai target MDG 2015 sebesar 23 per 1.000 kelahiran hidup. Penyebab kematian bayi di Indonesia pada minggu pertama kehidupan adalah komplikasi kehamilan dan persalinan seperti asfiksia, sepsis, dan komplikasi berat lahir rendah. Penyebab kematian bayi baru lahir salah satunya disebabkan oleh asfiksia (27\%) yang merupakan penyebab kedua kematian bayi baru lahir setelah BBLR (Kementrian Kesehatan Republik Indonesia, 2015).

Di Propinsi Sulawesi Selatan tahun 2014 Angka Kematian Neonatal (AKN) menunjukkan sebesar 762 kasus yaitu 5.22 per 1.000 kelahiran hidup dan jumlah kematian bayi (AKB) sebesar 
1.056 bayi atau 7.23 per 1000 kelahiran hidup. Salah satu penyebab kematian bayi yang cukup banyak terjadi adalah kejadian kurangnya oksigen dalam rahim (hipoksia intra uterus) dan kegagalan nafas secara spontan dan teratur pada saat lahir atau beberapa saat setelah lahir (asfiksia lahir). Pada tahun 2012 angka kejadian asfiksia neonatorum sebanyak 151 kasus ( 16,59\%), dan pada tahun 2013 mengalami peningkatan yaitu sebanyak 212 kasus (21,74\%). (Dinas Kesehatan Provinsi Sulawesi Selatan, 2015).

Di kabupaten Bulukumba, Angka Kematian Bayi pada tahun 2013 tercatat 9 (4,07\%) kasus kematian atau 1,3 per 1.000 kelahiran hidup. Pada tahun 2014 tercatat 7 (1,89\%) kasus kematian atau 1,0 per 1.000 kelahiran hidup dan didominasi oleh kasus kematian neonatal yakni sebanyak 56 kasus atau 8,4 per 1.000 kelahiran hidup (Profil Kesehatan Kabupaten Bulukumba, 2014). Pada tahun 2015 tercatat $6(0,66 \%)$ kasus kematian per 1.000 kelahiran hidup. Hal ini menunjukkan adanya penurunan kasus dari tahun sebelumnya. Angka kejadian asfiksia pada tahun 2015 sebanyak 152 (2,53\%) dan sebanyak 4 (2,63\%) kasus bayi meninggal karena mengalami asfiksia. (Dinas Kesehatan Bulukumba, 2015).

Berdasarkan data dari Rsud H. A. Sulthan Daeng Radja Bulukumba diperoleh data yang menunjukkan bahwa. Pada tahun 2016 terdapat 1526 jumlah persalinan. Persalinan lewat bulan sebanyak $130(8.51 \%)$. Dari keseluruhan jumlah persalinan lewat bulan $77(59.23 \%)$ bayi lahir yang mengalami asfiksia dengan nilai apgar $<8$.

Kebijakan pemerintah dalam menangani permasalahan asfiksia yaitu dengan adanya program PONED dan PONEK yang diharapkan dapat menurunkan derajat kesakitan dan meminimalkan jumlah kematian para ibu dan bayi di Indonesia. Pelayanan neonatal yaitu pencegahan dan penanganan asfiksia, pencegahan dan penanganan hipotermi, pencegahan dan penanganan BBLR, pencegahan dan penanganan kejang atau ikterus, pencegahan dan penanganan gangguan minum

Tujuan penelitian ini adalah untuk mengetahui apakah ada hubungan antara kehamilan lewat bulan dengan kejadian asfiksia neonatorum di RSUD H. A. Sultan Daeng Radja Bulukumba

\section{METODE PENELITIAN}

\section{Desain Penelitian}

Desain penelitian yang digunakan dalam penelitian ini adalah survey analitik dengan pendekatan kohort historikal yang merupakan rancangan penelitian dengan melakukan pengamatan dengan melihat riwayat kohort. 


\section{Populasi dan Teknik Sampel}

Populasi adalah wilayah generalisasi yang terdiri atas objek/subjek yang mempunyai kuantitas dan karakteristik tertentu yang ditetapkan oleh peneliti untuk dipelajari dan kemudian ditarik kesimpulannya (Hidayat, 2014). Populasi dalam penelitian ini adalah seluruh ibu bersalin di Rsud H. A. Sulthan Daeng Radja Bulukumba baik persalinan normal maupun persalinan dengan tindakan sebanyak 1526.

Penarikan sampel menggunakan teknik Probability sampling dengan jenis sistematik random sampling yaitu dengan melakukan undian dari nomor 1-10 sehingga sampel pertama dapat ditentukan dari hasil undian tersebut. Kemudian untuk menetukan sampel selanjutnya dengan cara jumlah populasi dibagi dengan jumlah sampel, sehingga hasil bagi tersebut dapat dijadikan kelipatan untuk menentukan sampel selanjutnya.

\section{Instrumen Pengumpul Data}

Instrumen yang digunakan dalam penelitian ini adalah observasi (cheklist). Observasi merupakan cara pengumpulan data dengan mengadakan pengamatan secara langsung kepada responden penelitian untuk mencari perubahan atau hal-hal yang akan diteliti (Hidayat, 2014).

\section{Analisis Data}

Data dianalisis berdasarkan skala ukur dan tujuan penelitian dengan menggunakan perangkat lunak program komputerisasi. Data dianalisis secara : (1). Analisis Univariat, Analisis dilakukan untuk melihat proporsi. (2). Analisis Bivariat, Uji bivariat dilakukan untuk mencari hubungan antara variabel independen dan variabel dependen dengan uji yang digunakan adalah chi-square bila memenuhi syarat, $\alpha=0.05$ dan melihat nilai Resiko relative (RR).

\section{HASIL}

\section{Karakteristik responden}

Berdasarkan tabel 1 menunjukkan bahwa responden dengan umur terbanyak pada penelitian ini adalah berusia 20-35 tahun yaitu sebanyak 223 orang (72.6\%). Sedangkan responden dengan umur $>35$ tahun sebanyak 59 orang (19.2\%) dan responden dengan umur <20 tahun sebanyak 25 orang $(8.1 \%)$.

Berdasarkan paritas ibu, menunjukkan bahwa responden dengan paritas terbanyak pada penelitian ini adalah responden dengan paritas multipara yaitu sebanyak 149 (48.5\%), responden dengan paritas primipara sebanyak 141 orang (45.9\%) dan responden dengan paritas grande multipara sebanyak 17 orang $(5.5 \%)$. 


\section{Volume 1, Nomor 1, April 2017 \\ JURNAL LIFE BIRTH \\ p-ISSN: 2580-0574 : e-ISSN:}

Tabel 1. Distribusi karakteristik responden berdasarkan umur dan paritas

\begin{tabular}{ccc}
\hline Karakteristik & Frequensi (f) & Presentase (\%) \\
\hline Umur & & \\
$<20$ Tahun & 25 & 8.1 \\
20-35 Tahun & 223 & 72.6 \\
$>35$ Tahun & 59 & 19.2 \\
Paritas & & \\
Primipara & 141 & 45.9 \\
Multipara & 149 & 48.5 \\
Grande Multipara & 17 & 5.5 \\
\hline Total & $\mathbf{3 0 7}$ & $\mathbf{1 0 0 . 0}$ \\
\hline
\end{tabular}

\section{Analisis Univariat}

Berdasarkan tabel 2 menunjukkan bahwa jumlah ibu bersalin terbanyak adalah pada usia kehamilan aterm yaitu sebanyak 279 orang $(90.9 \%)$ dan responden yang mengalami kehamilan lewat bulan sebanyak 28 orang $(9.15 \%)$, sedangkan jumlah bayi yang lahir terbanyak yaitu bayi dengan nilai APGAR score $>7$ atau bayi yang tidak mengalami asfiksia neonatorum sebanyak 239 bayi (77.9\%) dan bayi yang mengalami asfiksia sebanyak 68 bayi $(22.1 \%)$.

Tabel 2. Distribusi Jumlah Responden Berdasarkan Usia Kehamilan Lewat Bulan Dan Asfiksia

\begin{tabular}{ccc}
\hline Lewat Bulan & Frequensi (f) & Presentasi (\%) \\
\hline Ya & 28 & 9.1 \\
Tidak & 279 & 90.9 \\
\hline Total & $\mathbf{3 0 7}$ & $\mathbf{1 0 0 . 0}$ \\
\hline Asfiksia & Frequensi (f) & Presentase (\%) \\
\hline Ya & 68 & 22.1 \\
Tidak & 239 & 77.9 \\
\hline Total & $\mathbf{3 0 7}$ & $\mathbf{1 0 0 . 0}$ \\
\hline
\end{tabular}

\section{Analisis Bivariat}

Berdasarkan tabel 3 menunjukkan persalinan lewat bulan 16 bayi (57.1\%) mengalami asfiksia lebih besar bila dibandingkan dengan yang tidak mengalami asfiksia sebanyak 12 bayi (42.9\%). Begitu pula dengan persalinan yang tidak lewat bulan, bayi yang mengalami asfiksia 
sebanyak 52 (18.6\%) lebih kecil bila dibandingkan dengan bayi yang tidak mengalami asfiksia sebanyak $227(81.4 \%)$.

Dari hasil analisa hubungan kehamilan lewat bulan dengan kejadian asfiksia neonatorum dengan menggunakan uji Chi-Square didapatkan hasil uji Pearson Chi-Square dengan nilai $p$ value 0.000 dengan $\alpha=0.05, p<\alpha$ berarti ada hubungan antara kehamilan lewat bulan dengan kejadian asfiksia dengan nilai Resiko Relative $(R R)$ sebesar 3.066 artinya ibu yang mengalami kehamilan lewat bulan beresiko 3 kali lebih besar melahirkan bayi asfiksia dibandingkan dengan ibu hamil aterm.

Tabel 3. Hubungan kehamilan lewat bulan dengan kejadian asfiksia neonatorum

\begin{tabular}{|c|c|c|c|c|c|c|c|c|}
\hline \multirow{3}{*}{$\begin{array}{c}\text { Kehamilan Lewat } \\
\text { Bulan }\end{array}$} & \multicolumn{4}{|c|}{ Kejadian Asfiksia } & \multirow{3}{*}{$\mathbf{F}$} & \multirow{3}{*}{$\%$} & \multirow{3}{*}{$\begin{array}{c}\text { P- } \\
\text { Value }\end{array}$} & \multirow{2}{*}{$\mathbf{R R}$} \\
\hline & \multicolumn{2}{|c|}{ Ya } & \multicolumn{2}{|c|}{ Tidak } & & & & \\
\hline & $\mathbf{N}$ & $\%$ & $\mathbf{N}$ & $\%$ & & & & \\
\hline Lewat Bulan & 16 & 57.1 & 12 & 42.9 & 28 & 100.0 & 0.000 & 3.066 \\
\hline Tidak Lewat Bulan & 52 & 18.6 & 227 & 81.4 & 279 & 100.0 & & \\
\hline Total & 68 & 22.1 & 239 & 77.9 & 307 & 100.0 & & \\
\hline
\end{tabular}

\section{PEMBAHASAN}

Pada penelitian ini terlihat bahwa terdapat hubungan yang signifikan antara kehamilan lewat bulan dengan kejadian asfiksia neonatorum di rsud H. A. sulthan daeng Radja Bulukumba

Bayi yang mengalami asfiksia sebagian besar dilahirkan dari ibu yang mengalami kehamilan lewat bulan. Berdasarkan hasil analisis data menggunakan uji Chi-Square didapatkan hasil uji Pearson Chi-Square dengan nilai $p$-value 0.000 dengan $\alpha=0.05, p<\alpha$ dengan demikian tidak ada alasan menolak Ha, artinya secara statistik terdapat hubungan antara kehamilan lewat bulan dengan kejadian asfiksia dengan nilai Resiko Relative (RR) sebesar 3.066 artinya ibu yang mengalami kehamilan lewat bulan beresiko 3 kali lebih besar melahirkan bayi asfiksia dibandingkan dengan ibu yang tidak mengalami kehamilan lewat bulan. Hasil penelitian ini sejalan dengan hasil penelitian (Mulia, 2014) ada hubungan antara kehamilan post term dengan kejadian asfiksia dengan nilai p-value 0,013 dengan nilai Odds ratio 3,571. Jadi, terdapat hubungan kehamilan lewat bulan dengan kejadian asfiksia neonatorum. Hal ini terjadi karena kehamilan yang berlangsung selama 42 minggu atau lebih menyebabkan plasenta terus mengalami penuaan yang pada akhirnya berdampak pada penurunan fungsi plasenta itu sendiri 
sehingga terjadi gangguan sirkulasi oksigen dari ibu ke janin yang dapat menyebabkan gangguan pernapasan pada janin.

\section{KESIMPULAN DAN SARAN}

Berdasarkan hasil penelitian diatas maka dapat disimpulkan bahwa terdapat hubungan yang singnifikan antara kehamilan lewat bulan dengan kejadian asfiksia neonatorum di Rsud H. A. Sulthan Daeng Radja bulukumba Tahun 2016 dengan insiden kehamilan lewat bulan sebanyak $28(9.1 \%)$ dan asfiksia sebanyak $68(22.1 \%)$. Hasil penelitian ini diharapkan bagi petugas kesehatan agar lebih teliti lagi dalam menentukan usia dan taksiran persalinan serta mengetahui faktor-faktor penyebab asfiksia sehingga petugas selalu siap memberikan pelayanan secara komprehensif dalam penanganan kasus kegawatdaratan dan bagi rumah sakit agar selalu secara terus menerus meningkatkan kualitas pelayanan dan tindakan yang dilakukan dalam hal peningkatan pelayanan pada ibu dan bayi baru lahir.

\section{DAFTAR PUSTAKA}

Arfiana, \& Arum, L. (2016). Asuhan Neonatus Bayi Balita dan Anak Pra Sekolah. Yogyakarta: Transmedika.

Brillianningtyas at al. (2013). Hubungan Kehamilan Lewat Waktu dan Bayi Prematur dengan Kejadian Asfiksia Neonatorum. Hal. 100

Buku Acuan Midwifery Update. (2016). Jakarta: Pengurus Pusat Ikatan Bidan Indonesia.

Buku Saku Pelayanan Kesehatan Ibu Dasar dan Rujukan (2013). Jakarta.

Dina Hartatik. (2013). Pengaruh Umur Kehamilan Pada Bayi Baru Lahir Dengan Kejadian Asfiksia Di RSUD Dr. Moewardi Surakarta. Vol. 10(1), Hal 71-76

Dinas Kesehatan Kabupaten Bulukumba. (2015). Hal. 28-29

Dinas Kesehatan Provinsi Sulawesi Selatan. (2015). Profil Kesehatan Provinsi Sulawesi Selatan 2014. Hal. 17-20

Dwienda et al. (2014). Buku Ajar Asuhan Kebidanan Neonatus, Bayi/ Balita dan Anak Prasekolah untuk Para Bidan. Yogyakarta: Deepublish.

Hidayat, A. A. (2014). Metode Penelitian Kebidanan dan Teknik Analisis Data. Jakarta: Salemba Medika.

Ika, F. E. (2015). Asuhan Kebidanan Neonatus Bayi, Balita dan Anak Pra Sekolah. Jakarta: TIM 
Kementrian Kesehatan Republik Indonesia. (2015). Hal. 124-125

Manggiasih, \& Pongki, J. (2016). Buku Ajar Asuhan Kebidanan Pada Neonatus, Bayi, Balita dan Anak Pra Sekolah. Jakarta: Tim.

Martaadisoebrata et al. (2013). Obstetri Patologi Ilmu Kesehatan Reproduksi. Jakarta: EGC.

Mulia, U. P., \& Sulistyaningsih. (2014). Hubungan Kehamilan Post Term Dengan Kejadian Asfiksia Pada Bayi Baru Lahir Di Rsu Pku Muhammadiyah Bantul Tahun 2013 . Hal. 5

Nugroho, T. (2012). Patologi Kebidanan. Yogyakarta: Nuha Medika.

Nurmayawati, D. (2014). Hubungan Kehamilan Lewat Waktu (Postterm) dengan Kejadian Asfiksia Pada Bayi Baru Lahir.

Oxorn, \& William, R. F. (2010). Ilmu Kebidanan: Patologi Dan Fisiologi Persalinan.

Yogyakarta: ANDI; YEM.

Pelatihan Penanganan Kegawatdaruratan Maternal Dan Neonatal Tahap Awal (Poned). (2012).

Rekam Medik Rsud H. A. Sulthan Daeng Radja Bulukumba. (2014-2016).

Respatiningrum et al. (2013). Hubungan Kejadian Asfiksia Neonatorum dengan Perkembangan Bayi Usia 6-12 Bulan Di Ruang Anggrek Rsud Kota Tanjungpinang Tahun 2012.

Rukiyah, A. Y., \& Lia, Y. (2013). Asuhan Neonatus Bayi dan Anak Balita. Jakarta: TIM.

Sabri, L., \& Sutanto, P. H. (2014). Statistik Kesehatan. Jakarta: Rajawali Pers.

Saifuddin, A. B. (2014). Ilmu Kebidanan Sarwono Prawirohardjo. Jakarta: PT Bina Pustaka.

Sugiyono. (2012). Metode Penelitian Kuantitatif Kualitatif dan R\&D. Bandung: Alfabeta

Sukmawati, L. (2016). Hubungan Kehamilan Postterm Dengan Kejadian Asfiksia Neonatorum Di Rsud Ambarawa Tahun 2015 . Hal. 7-9

Suriani, \& Ardian, A. (2015). Faktor-Faktor Yang Mempengaruhi Kehamilan Lewat Waktu (Serotinus) Di Rsud Pangkep. Hal. 741-742

Wahyu, U. E. (2015). Pengaruh Umur Ibu, Paritas, Usia Kehamilan, dan Berat Lahir Bayi Terhadap Asfiksia Bayi Pada Ibu Pre Eklamsia Berat. Hal.5-6 